Original Article

\title{
PREVALENCE OF PSYCHIATRIC DISORDERS AMONG ELDERLY IN-PATIENTS IN NON-PSYCHIATRIC WARDS OF A TEACHING HOSPITAL IN NORTHERN NIGERIA
}

\author{
Amedu M.A, ${ }^{1}$ Yusuf A.J, ${ }^{2}$ Baiyewu $O .^{3}$ \\ ${ }^{I}$ Department of Psychiatry, Federal Medical Centre, Makurdi, ${ }^{2}$ Ahmadu Bello University Teaching Hospital, Zaria, and ${ }^{3}$ University \\ College Hospital, Ibadan.
}

*Corresponding Author: Amedu A. Michael, Department of Psychiatry, Federal Medical Centre, Makurdi, Nigeria. Tel: +2348065768486 .

Published: November $23^{\text {rd }} 2018$.

\section{Abstract}

The population of the elderly is increasing globally with enormous challenges particularly in developing countries. Aging increases the risk for both physical and psychiatric disorders with psychiatric disorders often unrecognized in non-psychiatric settings. This presents huge costs to both patient and society. The study aimed at estimating the rate of psychiatric morbidity in non-psychiatric wards of a tertiary hospital in Northern Nigeria. One hundred and forty (140) subjects were recruited into this cross-sectional descriptive study. Participants were initially screened using the Self Reporting Questionnaire (SRQ) and the Modified Mini-Mental State Examination (MMSE) after administering the Socio-demographic questionnaire. Subjects scoring $>5$ in the SRQ and or $\leq 13$ in the Modified MMSE were then further interviewed using the Geriatric Mental State Schedule (GMS). Clinical Psychiatric diagnosis was also made based on ICD-10 diagnostic criteria from all information available and later compared with GMS diagnoses. Mean age of participants was 67.5, SD \pm 6.4 . The rate of psychiatric morbidity using ICD-10 diagnosis was $47.9 \%$ with depression being the commonest disorder (18.6\%) followed by delirium $(17.1 \%)$ and dementia (10.7\%). Depression and anxiety disorders were particularly under-recognized by nonpsychiatric doctors. Identified risk factors for psychiatric morbidity included female gender, low socioeconomic status, low educational level and presence of multiple medical diagnoses. The rate of psychiatric morbidity among elderly in-patients in non-psychiatric settings has remained high in comparison to previous studies with huge gaps in recognition and treatment reflecting the need for more collaboration between medical teams.

Keywords: Elderly, Non-psychiatric wards, Northern Nigeria, Psychiatric Disorders

\section{Introduction}

Advances in technology, medical care, new drugs and improvement in living conditions is producing an increase in the population of older adults globally, thereby altering the scope and depth of clinical practice. $^{1,2}$ Demographic forecasts predict that by 2030, one person in five will be over the age of $65 .^{3}$ Already, projections have shown that by 2020, the population of those aged 65 and older will outnumber children younger than 5 years. ${ }^{4}$ This rise in ageing of population will be particularly pronounced in developing countries. The World Health report of 2003 estimated that by the year 2020 the population of the elderly will reach an alarming figure of 1.2 billion with majority of them living in the developing countries which are now experiencing rapid shifts from high mortality and high fertility to much reduced fertility and greater longevity. ${ }^{5,6}$ Nigeria is also witnessing this demographic shift as reflected in the government vital document of economic and social development strategy. ${ }^{7}$ The elderly are vulnerable to illnesses, particularly psychiatric illness. Medical comorbidities aggregate with age and constitute the most important factor distinguishing older patients from younger ones ${ }^{3}$. Many mentally ill elderly end up in non-psychiatric wards due to somatisation of psychological symptoms or when symptoms are attributed to old age and consequently treated lightly or dismissed. ${ }^{8}$ Studies have suggested that standardized psychiatric instruments developed in the western world to detect psychiatric symptoms may potentially ignore culture specific idioms of distress when used in non-western African cultures and thus, 
fail to give a true picture of the burden. ${ }^{9}$ The elderly also have increased risk of suicide which is often associated with feelings of loneliness, poor medical health, financial difficulties and depression. ${ }^{10-12}$

Studies from developed countries like the US have found the rate of Psychiatric morbidity among various elderly in-patients groups to range between $40 \%$ and $50 \% .^{13}$ In India, Sood $^{14}$ found a rate of $49 \%$ with Depression being the commonest mental illness. Uwakwe $^{15}$ in Southwest Nigeria found the rate of psychiatric morbidity to be $45.3 \%$ with depression being the commonest disorder $(22.6 \%)$. Sokoya and Baiyewu, ${ }^{16}$ while assessing geriatric depression among primary care attendees in Ibadan, Oyo state used the GMS to make diagnosis of depression, but used the Geriatric Depression Scale to initially screen the participants. They found the rate of geriatric depression to be $7.4 \%$ lower than findings for geriatric inpatients.

This study seeks to assess the rate of psychiatric morbidities among elderly in-patients in nonpsychiatric wards in our environment. A study of this nature was carried out by Uwakwe et al, ${ }^{15}$ over two decades ago in Mid-Western Nigeria, a region that is geographically and culturally distinct from that of Northern Nigeria (with lower literacy levels and more gender socio-economic disadvantage). ${ }^{17,18}$ This study will thus contribute to the sparse literature that exists on the elderly in many developing nations and will serve as reference for health workers with interest in the medical and psychological wellbeing of the elderly and thus facilitate collaboration between these specialties. This study will also help guide policy formation and legislation as it relates to our senior citizens considering the almost non-existent geriatric centers in the country. ${ }^{12,19}$

\section{Materials and Methods}

\section{Participants}

Elderly inpatients in non-psychiatric wards of the Ahmadu Bello University Teaching Hospital Zaria, Northwest Nigeria, who were 60 years and above were recruited into the study. Age determination was based on verbal reports from subjects and their caregivers, and the use of historical events and landmarks for subjects who had no knowledge of their age, as used by Sokoya and Baiyewu ${ }^{16}$, and Yusuf et $a l .{ }^{20}$ Non-consenting subjects were excluded from the study. The sample size of 140 was determined based on a previous study by Uwakwe. ${ }^{15}$ This was calculated using the formula: $n=z^{2} P(1-P) / d^{2}$, where $n=$ desired sample size, $\mathrm{Z}=$ the standard normal deviate, $\mathrm{P}=$ the proportion in the target population estimated to have a particular characteristic. This was based on the prevalence study by Uwakwe et $a l^{15}$ in which a prevalence of $45 \%$ was obtained; $q=1.0-p$,

$\mathrm{d}=$ degree of accuracy desired. ${ }^{112,113}$

$\mathrm{n}=(1.96)^{2}(0.45)(1-0.45) / 0.05^{2}=380.318$ i.e. 380 .

This calculation applies when studying population that is $>10,000$. For population $<10,000$ the formula $\mathrm{nf}=$ $\mathrm{n} /(1+\mathrm{n} / \mathrm{N})$ where $\mathrm{nf}=$ the desired sample size when population is $<10,000 ; \mathrm{n}=$ the desired sample size when population is $>10,000 ; \mathrm{N}=$ the estimated population size.

NB: Lipowski ${ }^{13}$ in USA found that the elderly make up $30 \%$ of all in-patients in the medical and surgical wards and that this value is found to be stable over time. Though the study by Uwakwe et $a l^{15}$ found a value $16.1 \%$ representing the percentage of the elderly in medical, surgical, gynaecological and oncological wards, $30 \%$ of the total sample is employed in this calculation taking into consideration the difference in time and the rising trend in the number of elderly in the community and those resorting to modern orthodox treatment as against traditional treatment.

Hence, $30 \%$ of 540 (total number of hospital beds) = 162 ;

$\mathrm{nf}=380 /(1+380 / 162)=113.579$, this was rounded up to 140 .

All patients 60years and above who were admitted into the medical, surgical, gynaecological and oncology wards were recruited consecutively until the sample size was reached. The wards were visited three (3) times in a week so that all patients who met the inclusion criteria were not missed due to brief admissions. The study was conducted between June 2012 and March, 2013.

\section{Instruments}

Instruments used in the study included the Self Reporting Questionnaire (SRQ), a screening instrument developed by the $\mathrm{WHO}$ and validated in Nigeria, ${ }^{21}$ consisting of yes/no questions about common mental health symptoms. It was translated into the indigenous Hausa language by a bilingual expert for subjects who do not understand English language. A cut-off point of 5 was used for the study in consonance with study by Uwakwe et $a .^{15}$ The Modified Mini Mental State Examination (MMSE), is a modification of the MMSE developed by Folstein et $a l,{ }^{22}$ for rating cognitive function. It was modified by 
the Ibadan-Indianapolis Dementia Project taking into consideration the effect of education and cultural bias. Based on the normative values for Nigerians determined by the Project group, a cut-off point of 13 indicating cognitive impairment was used for the study due to the effect of lack of education. The Hausa version by Yusuf et $a l^{20}{ }^{20}$ was used for subjects who could not speak and write in English; the Geriatric Mental State Schedule (GMS) is an instrument of proven validity and reliability with a computer algorithm AGECAT used for measuring a wide range of psychopathology in the elderly. It has been used in Nigeria $^{15,16,23}$ and found to have a high agreement when compared with ICD-10 diagnosis. The Hausa version by Yusuf et $a l^{20}{ }^{20}$ was used for subjects who could not speak and write in English. The sociodemographic questionnaire took into consideration the broad socio-demographic variables of the study participants which included age, gender, marital status, level of education, occupational status, income, socioeconomic status (SES) etc. For the purpose of this study, the SES was classified into high, middle, and low based on the following: type of occupation; income; and educational level. ${ }^{24-26}$ Other factors considered include place of residence, land or house ownership, owning a car, other dependents etc. Subjects whose earnings amount to less than US $\$ 1$ per day, unemployed, primary educational level and below, and/or an unskilled labourer, fell in the low socioeconomic status; subjects in the professional cadre, with at least a tertiary educational attainment, and earnings amounting to US\$5 per day and above fall in the high SES; other subjects are then grouped in the middle SES.The SES of subjects' first degree relatives were used for subjects who were totally dependent on their relatives. At the time of this study, the naira ( $\$$ ) equivalent of the US\$ was $\$ 155.26$

Participants' case records were also assessed to determine the medical and any psychiatric diagnoses made by the attending physicians. Ethical approval was obtained from the Ethics and Scientific Committee of the Ahmadu Bello University Teaching Hospital, Zaria.

\section{Statistical Analysis}

Version 15 of the Statistical Package for Social Sciences (SPSS) was used to analyze the data. Descriptive statistics was calculated for all continuous variables. Frequency distribution and cross tabulation were generated. Tests of independence were carried out using chi-square test and t-test. Level of agreement between AGECAT diagnosis (the computerized algorithm for GMS diagnosis) and ICD10 was determined using kappa statistics. Statistical significance was set at 5\% level of probability.

\section{Results}

\section{Socio-demographic Variables}

A total of 140 subjects participated in the study with the male gender dominating $99(70.7 \%)$. Mean age was 67.5 (SD \pm 6.41), Table 1. None of the subjects declined consent. Only $7.9 \%$ of the participants were aged 80years and above. The mean age for the female subjects was 68.63 ( $\mathrm{SD} \pm 8.613$ ), and male subjects 67.05(SD \pm 5.216). Most of the subjects were married $116(82 \%)$. Subjects with no Western education constitute $58(41.4 \%)$, while $32(22.9 \%)$ had only primary, 28(20\%) secondary and 22(15.7\%) tertiary education. Those with Quranic education constitute $62.9 \%$ (88) of the participants. Notably, 77(55\%) were employed (a combination of self and government employees).Subjects with low socioeconomic status constituted $57.1 \%$ of the participants, while $57(40.7 \%)$ and $18(12.9 \%)$ were of middle and high socioeconomic status respectively (table 1 ).

The prevalence of psychiatric disorders among elderly in-patients in non-psychiatric wards, in this study using ICD-10 diagnostic criteria (fig 1) was $47.9 \%$ (CI: 8.357-76.796). Depression constituted 18.6\%, followed by delirium (17.1\%), dementia (10.7\%), Generalized Anxiety Disorders (6.4\%), psychoactive substance dependence (1.4\%) and Bipolar Affective Disorder $(0.7 \%)$. Nine $(6.4 \%)$ had dual diagnosis, hence the excess over $100 \%$ when the individual diagnoses are summed up.

Overall, rate of psychiatric diagnosis by nonpsychiatric physicians was $3.57 \%$ (5) which included one subject with depression and four subjects with delirium. The prevalence of psychiatric morbidity among the elderly using AGECAT was $47.0 \%$ with Organic Mental Disorders having the highest prevalence 31(22.1\%), followed by Depression 22 (15.7\%), Anxiety Disorders 9 (6.4\%), Drug Addiction 3 (2.1\%), and Bipolar Disorder 1 (0.7\%), Table 2. 
Table 1: Prevalence of Psychiatric Disorders by Socio-demographic Variable using ICD-10 Diagnostic Criteria

\begin{tabular}{|c|c|c|c|}
\hline \multirow[t]{2}{*}{ Variable } & \multicolumn{2}{|c|}{$\begin{array}{l}\text { Psychiatric Disorder using ICD- } \\
10 \text { criteria }\end{array}$} & \multirow[b]{2}{*}{ Statistics } \\
\hline & Present (\%) & sent $(\%)$ & \\
\hline \multicolumn{4}{|l|}{ Age } \\
\hline $60-64$ & $22(45.8)$ & $26(54.2)$ & \multirow{6}{*}{$\mathrm{t}=1.770, \mathrm{df}=138, \mathrm{p}=0.79$} \\
\hline $65-69$ & $16(45.7)$ & $19(54.3)$ & \\
\hline $70-74$ & $15(42.9)$ & $20(57.1)$ & \\
\hline $75-79$ & $6(54.5)$ & $5(45.5)$ & \\
\hline $80+$ & $8(72.7)$ & $3(27.3)$ & \\
\hline$<80$ & $59(45.7)$ & $70(54.3)$ & \\
\hline \multicolumn{4}{|l|}{ Gender } \\
\hline Male & $42(42.4)$ & $57(57.6)$ & \multirow{2}{*}{$\chi^{2}=3.999, \mathrm{df}=1, \mathrm{p}<0.05^{*}$} \\
\hline Female & $25(61.0)$ & $16(39.0)$ & \\
\hline \multicolumn{4}{|l|}{ Marital Status } \\
\hline Married & $52(44.8)$ & $64(55.2)$ & \multirow[t]{2}{*}{$\chi^{2}=2.489, \mathrm{df}=1, \mathrm{p}=0.115$} \\
\hline Not married & $15(62.5)$ & $9(37.5)$ & \\
\hline \multicolumn{4}{|l|}{ Educational } \\
\hline Level & & & \multirow{5}{*}{$\chi^{2}=9.829, \mathrm{df}=3, \mathrm{p}<0.05^{*}$} \\
\hline Non literate & $36(62.1)$ & $22(37.9)$ & \\
\hline Primary & $12(37.5)$ & $20(62.5)$ & \\
\hline Secondary & $13(46.4)$ & $15(53.6)$ & \\
\hline Tertiary & $6(27.3)$ & $16(72.7)$ & \\
\hline \multicolumn{4}{|l|}{$\begin{array}{l}\text { Socioeconomic } \\
\text { status }\end{array}$} \\
\hline Low & $45(69.2)$ & $20(30.8)$ & \multirow{3}{*}{$\chi^{2}=25.364, \mathrm{df}=2, \mathrm{p}<0.001^{*}$} \\
\hline Middle & $20(35.1)$ & $37(64.9)$ & \\
\hline High & $2(11.1)$ & $16(88.9)$ & \\
\hline \multicolumn{4}{|l|}{ Occupation } \\
\hline Employed & $33(42.9 \%)$ & $44(57.1)$ & \multirow[b]{2}{*}{$\chi^{2}=2.720, \mathrm{df}=1, \mathrm{p}=0.099$} \\
\hline Unemployed & $34(54.0 \%)$ & $29(46.0)$ & \\
\hline \multicolumn{4}{|l|}{ No. of Medical } \\
\hline \multicolumn{4}{|l|}{ Diagnosis } \\
\hline 1 & $24(36.4)$ & $42(63.6)$ & $\chi^{2}=1.923, \mathrm{df}=1, \mathrm{p}=0.165$ \\
\hline 2 & $25(49.0)$ & $26(51.0)$ & $\chi^{2}=0.287, \mathrm{df}=1, \mathrm{p}=0.537$ \\
\hline 3 & $17(77.3)$ & $5(22.7)$ & $\chi^{2}=8.099, \mathrm{df}=1, \mathrm{p}=0.004^{*}$ \\
\hline 4 & $1(100.0)$ & - & $\mathrm{t}=3.516, \mathrm{df}=138, \mathrm{p}<0.05^{*}$ \\
\hline
\end{tabular}

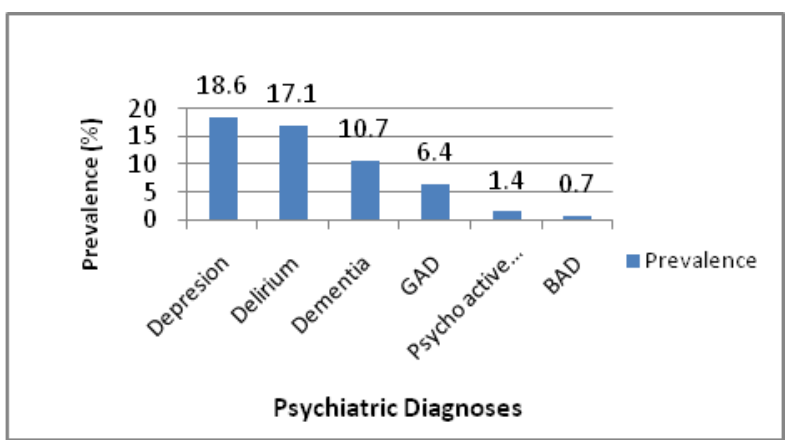

Fig 1: Bar Chart Showing the Prevalence of Psychiatric Morbidities among the Elderly in Non-Psychiatric Wards (\%) (Using ICD-10 diagnostic criteria)

GAD Anxiety Disorder, BAD Bipolar Affective Disorder

This is reflected in the high level of agreement between the ICD-10 diagnosis and AGECAT diagnosis as shown by the Kappa statistics in Table 3 .

The relationship between psychiatric morbidity and subjects' socio-demographic variables is also shown in Table 1. Female gender $\left(\chi^{2}=3.999 ; \mathrm{df}=1 ; \mathrm{p}<0.05\right)$, low socio-economic status $\quad\left(\chi^{2}=22.759 ; \quad \mathrm{df}=2\right.$; $\mathrm{p}<0.001)$, multiple medical diagnoses $(\mathrm{t}=3.777, \mathrm{df}=$, $\mathrm{p}<0.001)$, and low educational level $\left(\chi^{2}=9.829\right.$, $\mathrm{df}=3$, $\mathrm{p}<0.05)$ were all found to have a statistically significant relationship for psychiatric co-morbidity. There was no association between marital status and psychiatric co-morbidity $\left(\chi^{2}=2.489\right.$, df $\left.=1, \mathrm{p}=0.115\right)$ as well as being unemployed $\left(\chi^{2}=2.720, \mathrm{df}=1, \mathrm{p}=0.099\right)$. The relationship between age and psychiatric comorbidity $(\mathrm{t}=1.770, \mathrm{df}=138, \mathrm{p}=0.79)$ however, failed to reach statistical significance.

Table 2: Distribution of Psychiatric Morbidity by number of Medical Diagnosis and Socioeconomic Status using AGECAT diagnosis

\begin{tabular}{|c|c|c|c|c|c|c|c|c|}
\hline \multicolumn{2}{|c|}{ AGECAT Diagnoses (\%) } & \multicolumn{3}{|c|}{ No. of Medical Diagnosis } & \multicolumn{4}{|c|}{ Socioeconomic Status } \\
\hline & & $1(\%)$ & $2(\%)$ & $3(\%)$ & $4(\%)$ & Low (\%) & Middle (\%) & High (\%) \\
\hline Organic Mental Disorders & $31(22.1)$ & $8(5.7)$ & $10(7.1)$ & $12(8.6)$ & $1(0.7)$ & $20(14.3)$ & $11(7.9)$ & $0(0)$ \\
\hline Depression & $22(15.7)$ & $12(8.6)$ & $9(6.4)$ & $1(0.7)$ & $0(0)$ & $15(10.7)$ & $5(3.6)$ & $2(1.4)$ \\
\hline Anxiety Disorder & $9(6.4)$ & $2(1.4)$ & $5(3.6)$ & $2(1.4)$ & $0(0)$ & $8(5.7)$ & $1(0.7)$ & $0(0)$ \\
\hline Drug Addiction & $3(2.1)$ & $1(0.7)$ & $1(0.7)$ & $1(0.7)$ & $0(0)$ & $1(0.7)$ & $2(1.4)$ & $0(0)$ \\
\hline Bipolar Disorder & $1(0.7)$ & $1(0.7)$ & $0(0)$ & $0(0)$ & $0(0)$ & $0(0)$ & $1(0.7)$ & $0(0)$ \\
\hline No Diagnosis & $74(52.9)$ & $42(30.0)$ & $26(18.6)$ & $6(4.3)$ & $0(0)$ & $21(15.0)$ & $37(26.4)$ & $16(11.4)$ \\
\hline Total & $140(100)$ & $66(47.1)$ & $51(36.4)$ & 22(15.7) & $1(0.7)$ & $65(46.4)$ & $57(40.7)$ & $18(12.9)$ \\
\hline
\end{tabular}

Figures in brackets indicate percentages

Table 3: Relationship between SRQ, MMSE, and Psychiatric Diagnosis

\begin{tabular}{|c|c|c|c|c|c|c|c|c|}
\hline Sn & variables & $\begin{array}{l}\text { All Subjects } \\
\left(X_{ \pm}+\text {SD }\right)\end{array}$ & $\begin{array}{l}\text { ICD-10 } \\
\text { Diagnosis not } \\
\text { Present } \\
(\mathrm{X} \pm \mathrm{SD})\end{array}$ & $\begin{array}{l}\text { ICD-10 Diagnosis } \\
\text { present } \\
(\mathrm{X} \pm \mathrm{SD})\end{array}$ & t value & $\begin{array}{l}\text { GMS (AGECAT) } \\
\text { Diagnosis not } \\
\text { Present } \\
(\mathrm{X} \pm \text { SD) }\end{array}$ & $\begin{array}{l}\text { GMS (AGECAT) } \\
\text { Diagnosis Present } \\
(\mathrm{X} \pm \mathrm{SD})\end{array}$ & t value \\
\hline 1 & MMSE & $25.58 \pm 5.774$ & $25.58 \pm 3.057$ & $19.07 \pm 6.550$ & $\mathrm{t}=8.644 ; \mathrm{p}<0.001$ & $25.25 \pm 3.615$ & $19.05 \pm 6.563$ & $\mathrm{t}=5.000 ; \mathrm{p}<0.001$ \\
\hline 2 & SRQ 24 & $3.94 \pm 2.671$ & $2.64 \pm 2.009$ & $6.56 \pm 1.780$ & $\mathrm{t}=12.058 ; \mathrm{p}<0.001$ & $2.68 \pm 2.008$ & $6.82 \pm 1.530$ & $\mathrm{t}=1.042 ; \mathrm{p}<0.001$ \\
\hline
\end{tabular}




\section{Discussion}

\section{Socio-demographic Characteristics}

One hundred and forty subjects participated in this study. None of the participants declined consent. Subjects with impaired consciousness (delirium) had care givers who gave consent on their behalf.

The male to female ratio was found to be 2.4:1. Studies have shown a male preponderance in most medical and surgical wards, and psychiatric wards. ${ }^{14,15}$ This has been attributed to the tendency in Nigeria and many developing countries for male patients to be taken to the hospital so that they can quickly resume their socio-economic functions as bread winners in the family. ${ }^{15}$ This is also reflected in the community based study by Gureje et $a l,{ }^{9}$ on Depression among elderly Nigerians in the Ibadan Study of ageing where it was found that elderly males received more treatments for depression compared to their female counterpart. Male preponderance could be as a result of the frequently encountered low socioeconomic empowerment among the female gender in developing countries considering that patients usually make out of pocket payments in the hospital. Women in this age group are usually unemployed, without pension and dependent on their husbands or children. ${ }^{9,16,23}$ This is in addition to the low literacy level among the female sex in many developing countries as well as among women from Northern Nigeria (when compared to their counterpart from the Western and Eastern part of the country), ${ }^{18}$ taking into cognizance that level of education is a determinant of socioeconomic status and healthseeking behaviour; additionally, there is less value placed on women's health due to discrimination against women in a male dominated society; women would usually seek permission from their husbands before they can visit a healthcare centre. ${ }^{27}$

\section{Prevalence of Psychiatric Disorders}

Physical disorders are known to aggregate with ageing. ${ }^{1}$ The findings in this study reveal that the presence of multiple physical disorders ( $>2)$ positively correlates with the presence of psychiatric disorder(s) especially the organic mental disorders. Several reasons have been advanced to explain this phenomenon: the use of multiple drugs in the treatment of patients with more than a single diagnosis, which often have undesired side effects; the effect of the illness on the brain; the presence of psychiatric disorders which may have physical manifestation or complication. ${ }^{1,2,15}$
The prevalence of psychiatric disorders among elderly medical and surgical in-patients in this study is $47.9 \%$. This is similar to the findings by Uwakwe ${ }^{15}$, Nakasujja et $a l,{ }^{8}$ and Sood et al. ${ }^{14}$ Depression (18.6\%) is the commonest psychiatric co-morbidity found in this study similar to the findings by Uwakwe, ${ }^{15}$ Nakasujja et $a l^{8}$ and Soodet $\mathrm{al}^{14}$ and this was found to be largely unrecognized $135(96.1 \%)$. This perhaps reflects low index of suspicion for a psychological distress by the non-psychiatric physicians. This often comes at a huge cost to the patients and caregivers as it often results in unnecessary investigations, multiple drug use (with their attendant undesired side effects) and increasing length of hospital stay. ${ }^{28,29}$ Another reason for this non- or under-recognition is the somatisation of psychological distress frequently seen in the elderly. ${ }^{8,9,15}$ Psychological distress may also be given a cultural or religious undertone/ significance and as a result not volunteered as a symptom.

Delirium was more recognised by the physicians, $4(16.7 \%)$ often referred to as encephalopathy or acute confusional state thus, prompting a referral to the psychiatrist however, the rate of under-recognition still remained high $(83.3 \%)$. The reason for this underrecognition is attributed to the finding that Delirium in the elderly more frequently presents with the hypoactive type (in contrast to the hyperactive and mixed type) in which the patients are not disruptive thus, failing to attract clinical attention. ${ }^{30,31}$ The high prevalence of Delirium (Fig.1) could be due to polypharmacy in a setting of multiple medical diagnoses often encountered in the elderly. The risk for delirium is increased with drug-drug and drugillness interaction. It can also be attributed to the hospital setting, being a tertiary hospital receiving referrals from private and general hospitals of cases that may have had a better outcome had the referral and commencement of management been timely. It is noted here that most of the specialists are concentrated in the tertiary and teaching hospitals.

The rate of Dementia found in this study is $10.7 \%$. While Dementia and Delirium were found to be the commonest psychiatric disorders among elderly medical and surgical in-patients in some western studies, ${ }^{32,33}$ research from developing countries by Uwakwe $^{15}$, Sood et $a l^{14}$ and Nakasujja et $a l,{ }^{8}$ found lower rates for Dementia. Several reasons may explain this findings, these include: a more advanced demographic ageing in more industrialized countries and lower life expectancies in developing countries considering that age is a risk factor for dementia and 
most people will develop dementia if they live long enough, ${ }^{2,33}$ the finding in some studies from developing countries that elderly patients with dementia are only taken to the hospital for treatment when they begin to manifest with the Behavioural and Psychological Symptoms of Dementia (BPSD) as memory deficits alone is often considered a normal attribute of the aged; it could also be a reflection of the low prevalence of Dementia found in community based studies from some developing countries, ${ }^{20,33,34}$ finally, many elderly in the developed countries are either able to afford the cost of health care or are being catered for by their insurance health care providers and hence will readily present to the hospital for treatment. In most developing countries, health insurance policies are poorly formulated particularly those concerning the elderly. ${ }^{19,20}$ Several studies in the developing nations have found that many elderly are without pension or other forms of social security; while the payment of pensions are usually erratic, those on it find it difficult to cope with persistently rising inflation rate with the result that many elderly become completely dependent on their care givers for financial support noting that many hospital payments are out of pocket. ${ }^{20,35}$ Additionally, more technological advancement in the field of medicine with prompt response to medical emergencies in developed countries will ensure that more patients are reached and commenced on treatment promptly in contrast to developing countries where some of the patients with organic aetiology may die or develop irreversible complications before reaching specialist care.

Other psychiatric co-morbidities include: Generalizes Anxiety Disorder 9(6.4\%), Nicotine Dependence (Drug addiction using AGECAT) 2(1.4\%) and Biapolar Affective Disorder 1(0.7\%) (Fig. 1, Table 1). None of these were detected by the non-psychiatric doctors. This is also due to the poor recognition of psychological symptoms by untrained hands especially when these symptoms are somatised.

\section{Risk Factors for Psychiatric Co-morbidity}

Several studies have found an association between increasing age and the occurrence of psychiatric disorders especially Dementia and Depression. ${ }^{9,14,15,23}$ This is not reflected in this study $(\mathrm{t}=1.77, \mathrm{df}=138$, $\mathrm{p}=0.79$ ) and may be explained by the younger age cohorts as reflected by the mean age 67.51 (SD \pm 6.408 ) with $60-69$ years making up $59 \%$ of the cohort.
Of particular note in this study is the finding of a strong association between low socioeconomic status and psychiatric morbidity $\left(\chi^{2}=25.364, \mathrm{df}=2, \mathrm{p}<0.001\right)$. Several studies have reported this negative relationship. It may be explained by the findings that many elderly, especially in developing countries are without pension ${ }^{9,14,15,23}$ and are faced with challenges of poor social security, poverty, poor nutrition and inability to meet the increasing challenges of medical illness. Legislation in Nigeria concerning the elderly is either rudimentary or non-existent.

Female gender is found to be associated with psychiatric morbidity in this study $\left(\chi^{2}=3.999, \mathrm{df}=1\right.$, $\mathrm{p}<0.05)$, in consonance with findings from other studies by Yusuf et $a l,{ }^{20}$, Uwakwe ${ }^{15}$, Sokoya and Baiyewu ${ }^{16}$, Baiyewu et al, ${ }^{23}$ and Gureje et al. ${ }^{9}$ Studies have shown that the female gender is frequently associated with low socioeconomic status, unemployment, and low or absence of income, factors that are implicated in psychological morbidity.

Low educational level is found to be associated with increased psychiatric morbidity in this study $\left(\chi^{2}=9.829\right.$, df $\left.=3 \mathrm{p}<0.05\right)$. The protective effect of advanced educational level has been confirmed by several studies ${ }^{20,33,35}$ which is attributed to the positive effects of education in enhancing employment opportunities, better incomes and purchasing power, better health seeking behavior and access to quality health care. Educational activities which stimulate mental functions such as reading and writing have also been found to not only increase brain memory reserve but also keep dementia at bay. ${ }^{36}$

Medical co-morbidities aggregate with age and is considered the most important factor that distinguishes older and younger patients. ${ }^{3}$ This study found a relationship between increasing number of medical diagnosis and the occurrence of psychiatric morbidity in consonance with findings from other studies. Reasons advanced include, increasing dependency which restricts their movement and activity; multiple drug use, some of which may have behavioral side effects; effect of the illness on the brain and drug-illness interaction as seen in encephalopathies, dyselectrolytaemias, brain toxicities, and nutritional deficiencies. ${ }^{3,11,15,30}$

It is often assumed that the optimum treatment for someone with co-morbidities is to add together the treatments for the individual conditions. Additionally, clinical guidelines for chronic illnesses often focus on single disorders, even though most elderly with these disorders have multi-morbidity (two or more long- 
term disorders). ${ }^{37}$ The negative implications for the elderly who are experiencing progressive deficit in organ functions are grave. More so, therapeutic and adverse effects of medicines may also differ in those with multimorbidity. Furthermore, health systems have been accused of providing 20th-century medicine to today's elderly patient population services and intervention that are designed for young or middle-aged people with single disorders and discrete episodes of illness. This is further compounded by the fact that unidisciplinary and technical superspecialism has grown to dominate policy, research, practice and education at the peril of frail, older populations with multimorbidity. ${ }^{37}$

In many developing countries, the General Practitioners who are frequently the first point of contact for patients have little or no exposure in gerontology, geriatrics and geriatric psychiatry due to lack of specialists in these areas or lack of interest by the doctors.

\section{Conclusion}

The findings in this study brings to focus the persistence of high psychiatric morbidity among elderly medical and surgical in-patients despite advances in medicine, therapeutics and technology drawing attention on the need for a paradigm shift to treatments of elderly people which considers multimorbidity rather than single disorders, chronic disorders rather than acute or discrete episode disorders; harmonized holistic care rather than superspecialism; and the need for more collaboration between the psychiatric team and other medical teams. Mood and Anxiety disorders are particularly unrecognized. This study also finds a strong correlation between psychiatric co-morbidity and low socioeconomic status as well as the female gender, low educational level, and the presence of multiple medical diagnoses. There was however no relationship between psychiatric co-morbidity and age.

\section{Limitation}

The lack of relationship between age and psychiatric morbidity in this study may have been due to the preponderance of the young age group (60-69 years) of the participants. This can be better accounted for when the sample size is increased.

\section{Recommendations}

There is need for studies that focus on the outcome of social intervention for the elderly, as well as the effect of training specialists in the area of geriatrics and geriatric psychiatry.

\section{Conflict of Interest}

The authors declare no conflicts of interest

\section{References}

1. Fausi AS, Kasper DL, Longo DL, Braunwald E, Hauser SL, Jameson JL, et al. Geriatric Medicine, Harrison's Principle of Internal Medicine Part I, Ch 9, 2008.

2. Jeste DV, Geriatric Psychiatry Overview; in Kaplan and Sadock's Comprehensive Text Book of Psychiatry, $9^{\text {th }}$ Edition, 2009.

3. Soo B, Unutzer J; Geriatric Psychiatry, Psychiatric problems in the medically ill geriatric patients. Comprehensive textbook of psychiatry, 2009; 54.3b: 4025-4034.

4. Suzman R, Beard JR, Boerma T, Chatterji S. Health in an ageing world-what do we know? www.thelancet.com, [accessed 10-11-2015]

5. Kalasa B., Population and Ageing in Africa: a policy Dilemma. UNFPA 2001

6. World Health Organization. World Health Report 2003: shaping the future. Geneva. WHO 2003.

7. Ajomale OO, Country report: Ageing in NigeriaCurrent state, social and economic implication. ISA RCII, sociology of ageing, summer 2007.

8. Nakasujja N, Musisi S, Walugembe J, Wallace D. Psychiatric disorders among the elderly on nonpsychiatric wards in an African setting. Intpsychogeriatr 2007;19(4):691-704.

9. Gureje O, Kola L, Afolabi E, Epidemiology of major depressive disorder in the elderly Nigerians in the Ibadan study of ageing: a community-based survey. Lancet 2007; 370: 957-64.

10. Zoltán Rihma. Suicide in Psychiatric Diagnosis, Challenges and Prospects, 2009; 18:179-185.

11. Alexopoulos GS, Kelly RE. Geriatric Mood Disorders; Psychiatric Disorders of late life. In Kaplan and Sadock's Comprehensive Textbook of Psychiatry, $9^{\text {th }}$ Edn. 2009; Ch 54.3e; pp 4047-4058.

12. 10/66 Dementia Research Group. Dementia in developing countries, a consensus statement from the 10/66 dementia research group. Int $J$ Geriatr Psychiatry, 2000; 15:14-20.

13. Lipowsky $\mathrm{ZJ}$, The need to integrate liaison psychiatry and Geropsychiatry; Am J Psychiatry, 1983;140:10031005 . 
14. Sood A, Singh P, Gargi PD. Psychiatric morbidity in non-psychiatric geriatric in-patients. Indian $\mathbf{J}$ Psychiatry 2006; 48: 56-61.

15. Uwakwe R. Psychiatric morbidity in elderly patients admitted to non-psychiatric wards in a general/teaching hospital in Nigeria. Int J Geriatr Psychiatry 2000; 15:346-54.

16. Sokoya OO, Baiyewu O, Geriatric Depression in Nigerian Primary Care Attendees. Int $\mathbf{J}$ Geriatr Psychiatr 2003; 18:506-510.

17. Nigeria Literacy-Demographics. Index mundi. www.indexmundi.com/nigeria/literacy. 2014[accessed 28-03-2016].

18. Report of the National Literacy Survey. National Bureau of Statistics. 2010. www.nigerianstat.gov.ng. [accessed 27-03-2015].

19. Obashoro-John O, Global Aging Issues: the Nigerian Situation. The Journal of Ageing in Emerging Economies; December 2011.

20. Yusuf AJ, Baiyewu O, Sheikh TL, Shehu AU; Prevalence of Dementia and Dementia Subtypes among community-dwelling elderly people in northern Nigeria. IntPsychogeriatr 2011; 23:3:379-386.

21. Abiodun OA. Sensitivity and validity of the Self Reporting Questionnaire (SRQ) in Primary Health Care centre in Nigeria. PsychopathologieAfricaine, 1989 XXII:89-94.

22. Folstein M, Folstein S, McHugh P. Mini Mental State: A practical method for grading the cognitive state of patients for the clinician. Journal of psychiatric research, 1975;12:189-198.

23. Baiyewu O, Smith-Gamble V, Lane KA, Gureje O, Gao S, Ogunniyi A, Unverzagt FW, Hall KS, Hendrie HC. Prevalent estimates of depression in elderly community dwelling African American in Indianapolis and Yoruba in Ibadan, Nigeria. IntPsychogeriatr 2007;19(4): 679-89.

24. Akerele D, Adewuyi SA. Analysis of Poverty Profiles and Socioeconomic Determinants of Welfare among Urban Households of Ekiti State, Nigeria. Curr. Res. J. Soc. Sci., 2011; 3: 1-7.

25. Ajakaiye DO, Adeyeye VA. Concepts, Measurement and Causes of Poverty. CBN Economic and Financial Review. 39:1-32.

26. Grundy E, Holt E. The Socioeconomic Status of Older Adults: How should we measure it in studies of health inequalities? J Epidemiol Community Health 2001; 55:895-904.

27. Shaikh BT, Hatcher J. Health seeking behavior and health service utilization trends in National Health Survey of Pakistan: what needs to be done? J Pak Med Assoc, 2007;57(8):411-414.

28. Saravay SM, Steinberg MD, Weinschel B, et al. Psychological co-morbidity and length of stay in the general hospital. Am J Psychiatry, 1991;148:324-328
29. Wancata J, Benda N, Windhaber J, et al. Does psychiatric co-morbidity increase length of stay in general hospitals? Gen Hosp Psychiatry, 2001;23:8-14.

30. Kyomen HH, Whitfield TH. Psychosis in the Elderly. Am J Psychiatry, 2009: 166:2: 146-150.

31. Salawu FK, Danburam A, Ogualili P. Delirium: issues in diagnosis and management. Ann Afr Med, 2009; 8:139-46.

32. Engel G1, Romano J. Delrium, a syndrome of cerebral insufficiency. J Neuropsychiatry ClinNeurosci 2004; 16:526-38.

33. Baiyewu O. Dementia: in Psychiatric Diagnosis: Challenges and Prospects; edited by Solloum IM, Mezzich JE, Willey-Blackwill publishers, 2009;7:7183.

34. Uwakwe, R. The pattern of psychiatry disorders among the aged in a selective community. International Journal of Geriatric Psychiatry. 2000;15:355-362.

35. Idris S. Government and the Elderly in Nigeria. The Tide. Posted on 6-12-2012, accessed 06-02-2014.

36. Briggs $H$. Active brain keeps dementia at bay. www.bbc.com/news/health-23159127, [accessed 2212-2014].

37. Banerjee S. Multimorbidity-older adults need health care that can count past one. www.thelancet.com. [accessed 14-11-2014]. 